\title{
A Model for Cu-Se Resonant Tunneling Diodes Fabricated by Negative Template Assisted Electrodeposition Technique
}

\author{
Meeru Chaudhri ${ }^{1}$, A. Vohra ${ }^{1}$, S. K. Chakarvarti ${ }^{2}$ \\ ${ }^{1}$ Department of Electronic Science, Kurukshetra University, Kurukshetra, India \\ ${ }^{2}$ Department of Applied Physics, National Institute of Technology (Deemed University), Kurukshetra, India \\ E-mail: meerachaudhri@rediffmail.com
}

Received November 16, 2009; accepted December 29, 2009

\begin{abstract}
In this paper, the authors present and discuss a model for $\mathrm{Cu}-\mathrm{Se}$ nano resonant tunneling diodes (RTDs) fabricated by negative template assisted electrodeposition technique and formulate the mathematical equations for it. The model successfully explains the experimental findings.
\end{abstract}

Keywords: track-etch membrane, template synthesis, $\mathrm{Cu}$-Se resonant tunneling diodes, electrodeposition

\section{Introduction}

For nanoelectronics to become a reality one must be able to fabricate the devices and circuits at nanometer dimensions. For this, the researchers the world over have put in efforts in three different areas: nanofabrication, quantum modeling and circuit innovations. Modeling of a device is an essential part of this effort that provides a test bench and also forms the basis for simulation tools for the device. With the help of models, one can also adjust the structural parameters and keep at bay the undesirable parameters through device design and optimization while fabrication. However, the traditional device modeling is not valid in the nanometer regime [1]. Each of these areas has their own importance. As the nano dimensioned materials lead to new phenomenon and also possibly novel devices based on quantum tunneling mechanisms [2] a device theory that can properly treat quantum transport phenomenon is, therefore called for. In our previous publications [3-6], we have discussed the fabrication and the characterization of RTDs of various diameters made by utilizing different material systems. In this paper, we have developed a model for these RTDs. Equations have been formulated for this model and the experimental results have been verified with the help of these equations.

\section{Experimental}

$\mathrm{Cu}$-Se RTDs have been fabricated by electrodepositing $\mathrm{Cu}$ and $\mathrm{Se}$ in the pores of the polycarbonate track-etch membranes (PC TEMs) [3,4]. (PC TEMs) with pores of diameters $1 \mu \mathrm{m}, 100 \mathrm{~nm}$ and $40 \mathrm{~nm}$ were used for this purpose. The experimental set-up used to fabricate the
$\mathrm{Cu}-\mathrm{Se}$ RTDs is shown in the Figure 1.

TEM foils with in situ $\mathrm{Cu}-\mathrm{Se}$ binary structures were used for obtaining $\mathrm{I}-\mathrm{V}$ characteristics. However for SEM characterization, membranes were dissolved in the solvent dichloromethane $\left(\mathrm{CH}_{2} \mathrm{Cl}_{2}\right)$, should be leaving behind the structures. SEM view of $\mathrm{Cu}-\mathrm{Se} \mathrm{RTD}$ of diameter $1 \mu \mathrm{m}$ in back-scattering mode is shown in the Figure 2. This mode is used to obtain the contrast image of the object. In the figure, dark part is indicating Se and bright part is indicating $\mathrm{Cu}$.

An ohmic contact was made by applying Ag based paint on the top side of the Se to obtain I-V characteristics. Figure 3 illustrates the schematic cross-section of the samples in the pores of the membranes with the silver paste.

Experimental results of $\mathrm{I}-\mathrm{V}$ characteristics of $\mathrm{Cu}-\mathrm{Se}$ binary structures of diameters $2 \mu \mathrm{m}, 1 \mu \mathrm{m}, 100 \mathrm{~nm}$ and $40 \mathrm{~nm}$ are shown in Figures 4 and 5.

It is clear from the Figures 4 and 5 that a prominent feature of negative differential resistance region (NDR) appear as the diameter of the $\mathrm{Cu}$-Se binary structures reduces from $2 \mu \mathrm{m}$ to $1 \mathrm{~nm}$. This NDR increases with further reduction in the diameters of the $\mathrm{Cu}$-Se binary structures. The values of peak to valley current ratios (PVCRs) of $\mathrm{Cu}$-Se RTDs of different diameters are shown in Table 1.

\section{A Model for Cu-Se RTDs}

The structure consists of three different layers- $\mathrm{Cu}, \mathrm{Se}$ and Ag. As the quantum size effects in metals are normally seen at $1 \mathrm{~nm}$ [7], density of states (DOS) in $\mathrm{Cu}$ and $\mathrm{Ag}$ are expected to be continuous. It, thus behaves as a metal. Quantum size effects in semiconducting material 


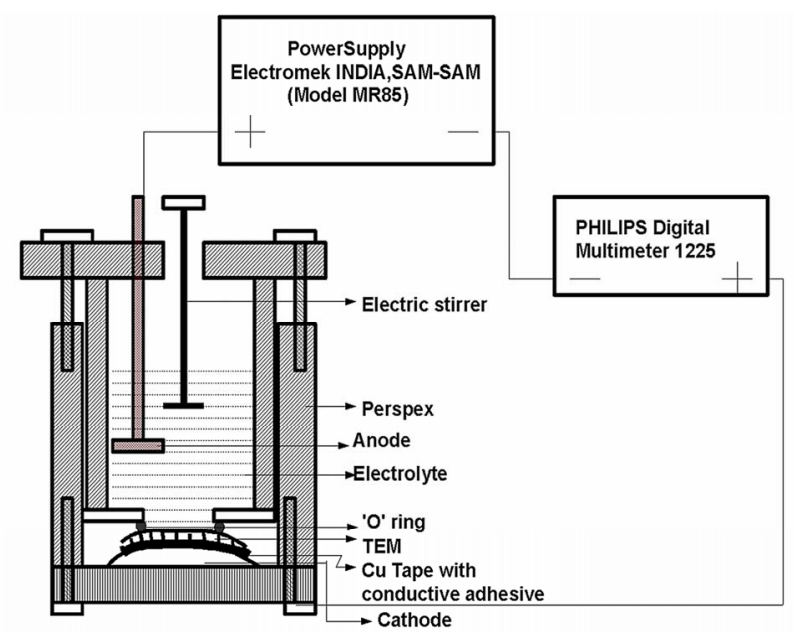

Figure 1. Experimental set-up for negative-template assisted electrodeposition of nano-/micro binary structures

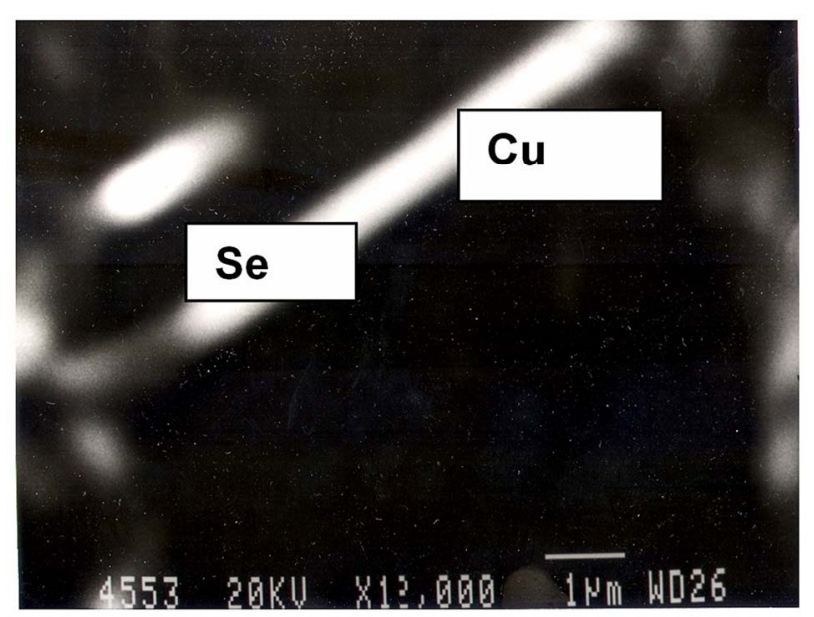

Figure 2. SEM micrograph of a template synthesized Cu-Se binary structure of $\mathbf{1} \boldsymbol{\mu m}$ diameter in back scattering mode

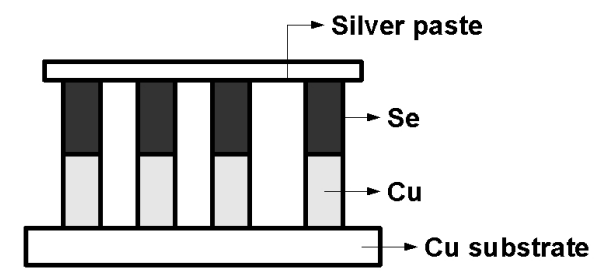

Figure 3. Samples with silver paste

become apparent when the size of the semiconducting material is of the order of hundreds of nanometers [8]. Thus, Se material has quantized bands as shown in Figure 6 (a), with infinite potential on the both sides of it i.e. Se semiconductor at small dimensions, forms a quantum well similar to the one fabricated by exploiting the energy band discontinuities of semiconductor heterostructures. The fabricated $\mathrm{Cu}-\mathrm{Se}-\mathrm{Ag}$ structure with wire shape,

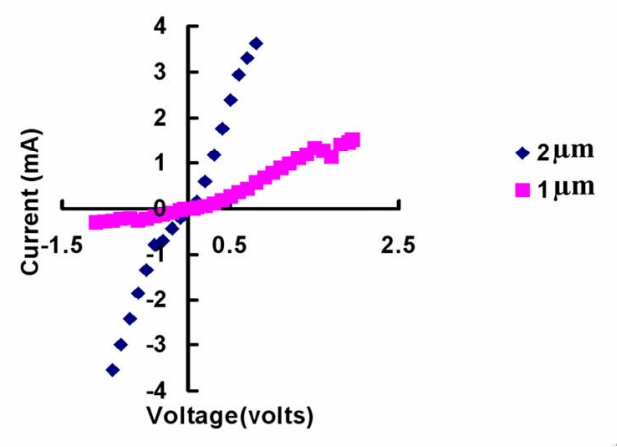

Figure 4. Experimental I-V characteristics of Cu-Se binary structures of $2 \mu \mathrm{m}$ and $1 \mu \mathrm{m}$ diameters

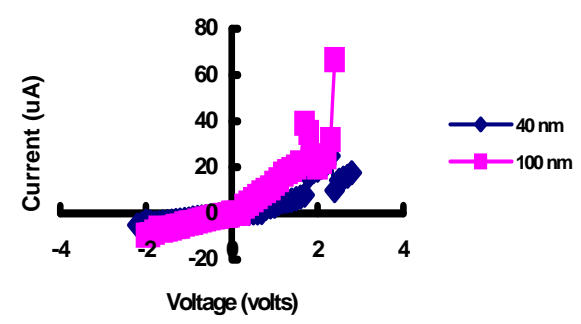

Figure 5. Experimental I-V characteristics of Cu-Se RTDs of $100 \mathrm{~nm}$ and $40 \mathrm{~nm}$ diameters

Table 1. Variation of PVCR with diameters of $\mathrm{Cu}$-Se devices

\begin{tabular}{cc}
\hline Diameter $(\mathbf{n m})$ & PVCR \\
\hline 40 & 2.5 \\
100 & 2.0 \\
1000 & 1.02 \\
\hline
\end{tabular}

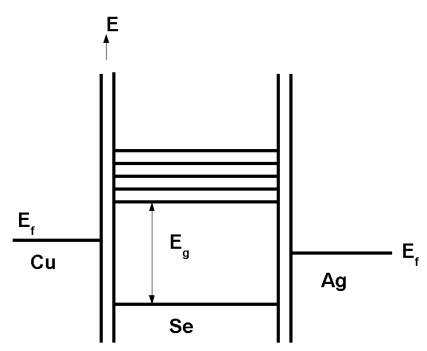

(a)

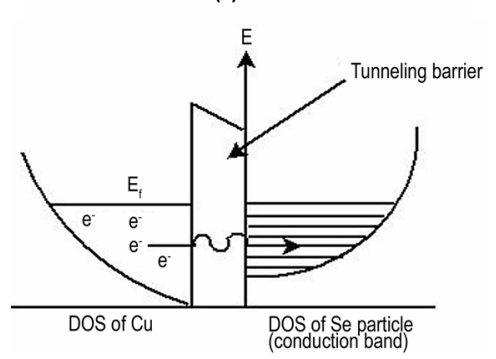

(b)

Figure 6. Model utilized for explaining the I-V characteristics of Cu-Se RTDs (a) equillibrium state (b) electrons flow from $\mathrm{Cu}$ to Se when a suitable voltage is applied across this system 
hence, forms one dimensional RTD with $\mathrm{Cu}$ as emitter, $\mathrm{Ag}$ as collector and Se as a potential well. On applying a voltage across the device, the band diagrams can be redrawn as shown in Figure 6(b). The electrons from the $\mathrm{Cu}$ electrode tunnel to the empty states in the conduction band of Se. The electrons in the well stay at a particular energy level until these electrons get enough energy to jump to the next higher energy level. These electron waves reflect back and forth between the two walls of the well and interfere, causing the change in the amplitude of the wave. When the energy of the electrons is equal to the energy of the quantized level in the well, the two waves interfere constructively and resonance of the electron wave takes place, which results in maximum transmission of electrons. The accumulation of electrons in the well thus results in a decrease in the current up to valley point current of the I-V curve.

Based on this model of quantization of energy levels, the I-V behavior of the $\mathrm{Cu}-\mathrm{Se}$ structures has been explained. The energy levels in $\mathrm{Cu}-\mathrm{Se}-\mathrm{Ag}$ structures can be drawn as in Figure 7. The bulk behavior of the $\mathrm{Cu}-\mathrm{Se}$ binary structures of $2 \mu \mathrm{m}$ can be explained by the energy level diagram of Figure 7 (a) where the energy levels are continuous.

However, as the dimensions of the device are reduced, quantized energy levels appear in Se semiconductor and a negative differential resistance region starts appearing. This is shown in Figure 7 (b). On reducing the diameter further, the negative differential resistance region increases and this is illustrated in Figure 7 (c). The energy band diagrams in Figures. 7 (b) and (c) show the increase in spacing in energy levels in the conduction band of the Se with decrease in the dimensions (diameter) of the fabricated binary structures.

Further, the cut-in voltages of the devices increase with decrease in diameters of the device. This indicates an increase in the Schottky barrier height due to increase in band gap of Se as the device dimensions are reduced. Various workers $[9,10]$ have reported an increase in band gap with reduction in dimensions. A similar behavior is expected for Se as well and has been shown in Figures 7(a), (b) and (c).

\section{Theoretical Analysis of Experimental Results}

In this section, the authors intend to correlate some of the experimental observations. Figures 4 and 5 and Table 1 indicate that there is 1) an increase in cut-in voltage as the diameters of the device is decreased 2) The PVCR increases with decrease in diameters of the device.

\subsection{Increase in Cut-In Voltage}

The increase in cut in voltage as seen in Figs. 4 and 5 can be explained due to increase in band gap. Such an increase in band gap with decrease in diameter is reported in literature [10-12].

As a metal is brought in contact with a semiconductor, a barrier will be formed at the metal-semiconductor interface. The height of the barrier is governed by metal work function and the electron affinity of the semiconductor. The voltage required to increase the energy of electrons on the metal side to overcome the barrier is cut-in voltage. The cut-in voltage and the band gap of the semiconductor are related as [13].

$$
\mathrm{q} \phi_{\mathrm{b}}=\mathrm{E}_{\mathrm{g}}-\mathrm{q}\left(\phi_{\mathrm{m}}-\chi\right)
$$

where

$$
\begin{aligned}
& \mathrm{E}_{\mathrm{g}} \text { is band gap of the semiconductor } \\
& \qquad \begin{array}{l}
\mathrm{q} \phi_{\mathrm{m}} \text { is work-function of the metal } \\
\mathrm{q} \phi_{\mathrm{b}} \text { is Schottky barrier height at the } \\
\text { metal- semiconductor }
\end{array}
\end{aligned}
$$

contact

$\mathrm{q} \chi$ is electron affinity of the semiconductor

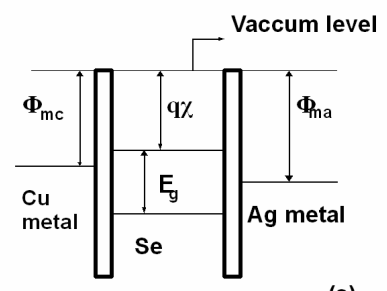

(i)

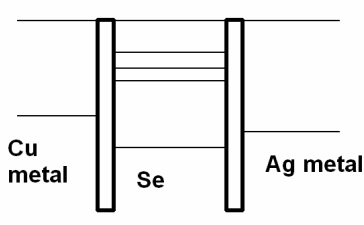

(i)

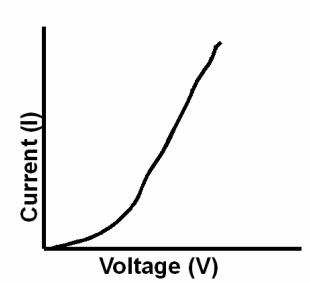

(ii)

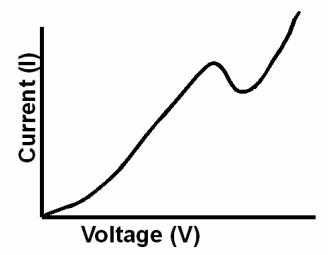

(ii)

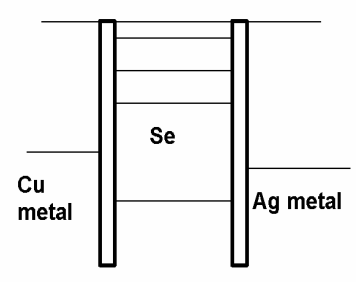

i

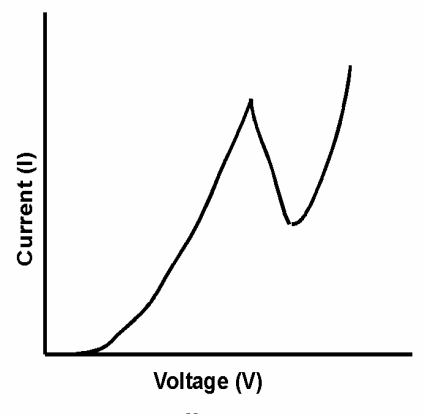

(c)

$\Phi_{\mathrm{mc}}$ is work function of Cu metal

$\Phi$ is work function of $\mathrm{Ag}$ metal

qX is electron affinity of Se

$E_{g}$ is band gap of Se

Figure 7. Energy band diagrams and corresponding I-V characteristics of Cu-Se resonant tunneling diodes of different diameters illustrating the emergence of quantum size effects (a) bulk effect (b \& c) quantum size effects 
From the Equation 1, it is clear that the cut-in voltage is directly dependent upon the band gap of the semiconductor material i.e. higher the band gap, higher will be the cut-in voltage. Klimov while studying the absorption spectra of CdSe material in bulk and in quantum dot form [14], found the appearance of quantized bands and an increase in band gap of CdSe in quantum dots. Further, the researcher also obtained an expression for the size dependent energy gap using the spherical "quantum box" model which is given below.

$$
\mathrm{E}_{\mathrm{g}}^{\text {band }}(\mathrm{d})=\mathrm{E}_{\mathrm{g}}^{\text {band }} \text { (bulk) }+\mathrm{h}^{2} / 8 \mathrm{~m}_{\mathrm{eh}} \mathrm{d}^{2}
$$

where

$$
\mathrm{m}_{\mathrm{eh}}=\mathrm{m}_{\mathrm{e}} \mathrm{m}_{\mathrm{h}} /\left(\mathrm{m}_{\mathrm{e}}+\mathrm{m}_{\mathrm{h}}\right)
$$

and $\mathrm{d}$ is the diameter of circular/cylindrical material $\mathrm{m}_{\mathrm{e}}$ is the effective mass of electron $\mathrm{m}_{\mathrm{h}}$ is the effective mass of hole

In Equation 2, the parameter ' $d$ ' introduces the size based effects. Equation 2 can be written as [15].

$$
\mathrm{E}_{\mathrm{g}}^{\text {band }}(\mathrm{d})=\mathrm{E}_{\mathrm{g}}^{\text {band }} \text { (bulk) }+\mathrm{K} / \mathrm{d}^{2}
$$

It is clear from Equation 3 that second term in Equation 3 tends to increase as the diameter of the device decreases. It implies that the value of band gap will increase as the diameter of the device is reduced. As the value of band gap increases, following Equation 1, the cut-in voltage will also increase.

Hence, the reduction in diameter of the device leads to an increase in the band gap of Se, which is indicated by an increase in cut-in voltage of the device.

\subsection{Tunneling Current}

Tunneling current I can be expressed by Equation 4 $[16,17]$

$$
I=\int T(E) \eta_{m}(E) \eta_{s}(E)\left[F_{m}(E)-F_{s}(E)\right] d E,
$$

where

$\mathrm{T}(\mathrm{E})$ is tunneling probability between the occupied level in the

$\mathrm{Cu}$ metal and the unoccupied level in the Se semiconductor

$\eta_{\mathrm{m}}(\mathrm{E})$ or $\eta_{\mathrm{s}}(\mathrm{E})$ is Density of states (DOS) of the metal and semiconductor, respectively

$\mathrm{F}_{\mathrm{m}}$ and $\mathrm{F}_{\mathrm{s}}$ is Fermi-distribution function in metal and

Semiconductor respectively

From the WKB (Wentzel-Kramers-Brillouin) approximation, the tunneling probability can be approximated as [17]

$$
\mathrm{T}(\mathrm{E}) \approx \exp (-2 \mathrm{kt})
$$

where

$\mathrm{k}$ is wave vector

$\mathrm{t}$ is width of the barrier

$$
\mathrm{F}_{\mathrm{m}} \text { and } \mathrm{F}_{\mathrm{s}}=1 /\left(1+\exp _{\mathrm{f}}^{\left(\mathrm{E}-\mathrm{E}_{\mathrm{fT}} / \mathrm{k}\right)}\right)[18]
$$

where, $E_{f}$ is Fermi energy of metal or semiconductor

Density of states in metals can be estimated by parabolic approximation, resulting in an $\mathrm{E}^{1 / 2}$ dependency of the density of states [18].

$$
\eta_{\mathrm{m}}=3.14 / 2 \times \text { volume } \times\left(8 \mathrm{~m}_{\mathrm{e}} \div \mathrm{h}^{2}\right)^{3 / 2} \times \mathrm{E}^{1 / 2}
$$

where $m_{e}$ is effective mass of an electron in the metal $h$ is the Planck's constant

However, the small size of Se semiconductor implies the presence of (Columbic) charging energy states in addition to the density of states of the particles. Taking into account the size distribution of the materials, we can express the density of states of the Se material as [17].

$$
\eta_{s}=\eta_{s}^{0} \sum_{n=0}^{n=\infty} \exp \left[-\left(E-n E_{c}\right) 2 /\left(2 \sigma^{2}\right) /\left(\sqrt{2 \pi \sigma^{2}}\right)\right.
$$

$\eta_{s}^{0}$ is density of states without the charging states and is given by [19]

$$
\eta_{s}^{0}=\sqrt{2 \pi m_{e}} / \sqrt{h^{2}} \times 1 / \sqrt{E}
$$

where $\eta_{s}$ is density of states of the Se

$\mathrm{E}_{\mathrm{c}}$ is charging energy of the Se

$\sigma$ is size-dependent standard deviation in energy space

As the spacing between the energy levels increases, $\sigma$ will increase as the size of the semiconductor decreases. The various parameters for $\mathrm{Cu}-\mathrm{Se}$ binary structures are given in Table 2.

The values of the various other parameters are given below.

$$
\begin{aligned}
& \text { Free mass of the electron }(\mathrm{m})=9.1 \times 10^{-31} \mathrm{~kg} \\
& \text { Planck's constant }(\mathrm{h})=6.602 \times 10^{-34} \mathrm{~J}-\mathrm{s} \\
& \mathrm{E}_{\mathrm{f}}(\mathrm{Cu})=7.0 \mathrm{eV}[23] \\
& \mathrm{E}_{\mathrm{f}}(\mathrm{Se})=5.6 \mathrm{eV}[21]
\end{aligned}
$$

\subsection{Calculation of Charging Energies for Se}

Charging energy is the energy required to put a charge $\mathrm{q}$ on a conductor of capacitance $\mathrm{C}_{0}$ and is given by $[24,25]$.

$$
\mathrm{E}_{\mathrm{c}}=\mathrm{e}^{2} / 2 \mathrm{C}_{0} \approx \mathrm{e}^{2} / 4 \pi \in_{0} \in_{\mathrm{r}} \mathrm{d}
$$

Table 2. Parameters of $\mathrm{Cu}, \mathrm{Ag}$ and Se materials

\begin{tabular}{ccccc}
\hline & $\begin{array}{c}\text { Work } \\
\text { function } \\
(\mathrm{eV})\end{array}$ & $\begin{array}{c}\text { Electron } \\
\text { affinity } \\
(\mathrm{eV})\end{array}$ & $\begin{array}{c}\text { Effective } \\
\text { mass } \\
(\mathrm{Kg})\end{array}$ & References \\
\hline $\mathrm{Cu}$ & 4.7 & & $1.46 \mathrm{~m}$ & {$[20]$} \\
$\mathrm{Se}$ & 5.11 & 3.0 & $0.22 \mathrm{~m}$ & {$[20-22]$} \\
$\mathrm{Ag}$ & 4.73 & & & {$[20]$} \\
\hline
\end{tabular}


where

$\epsilon_{0}$ is permittivity of free space $=8.854 \times 10^{-12} \mathrm{~F} / \mathrm{m}$

$\epsilon_{\mathrm{r}}$ is relative permittivity or dielectric constant of Se material $=6.1[26]$

$\mathrm{d}$ is diameter of the semiconductor

$\mathrm{e}$ is charge on an electron $=1.6 \times 10^{-19} \mathrm{C}$

Substituting the values of diameters of different $\mathrm{Cu}-\mathrm{Se}$ devices in Equation 7, correspondingly, charging energy comes out to be $0.0002 \mathrm{eV}$ ( $1 \mu \mathrm{m}$ diameter), $0.002 \mathrm{eV}$ (100 nm diameter) and $0.006 \mathrm{eV}$ (40 nm diameter). Since capacitance $\mathrm{C}_{0}$ is dependent directly on the diameter of the device, clearly the charging energy will increase as the diameter is reduced. Hence, an electron will be able to enter into the nanomaterial if it has enough charging energy and if it is in resonance with an empty state of the well. Substituting the values of parameters of $\mathrm{Cu}, \mathrm{Se}$ and $\mathrm{Ag}$ in Equations 5, 6, 7 and 8, $\eta_{\mathrm{m}}$, $\eta_{\mathrm{s}}, \mathrm{T}(\mathrm{E})$ and $\mathrm{F}_{(\mathrm{m} \text { or s) }}$ are calculated for different values of energies. Substituting the values of these terms in Equation 4, the variation of tunneling current in $\mathrm{Cu}$-Se RTDs of diameters $1 \mu \mathrm{m}, 100 \mathrm{~nm}$ and $40 \mathrm{~nm}$ for various values of voltages are calculated and plotted. The calculated I-V curves for different diameters are shown in Figures. 8, 9 and 10.

From Figures 8, 9 and 10, we observe that the theoretical I-V characteristics of the $\mathrm{Cu}-\mathrm{Se}$ binary structures of diameters $1 \mu \mathrm{m}, 100 \mathrm{~nm}$ and $40 \mathrm{~nm}$ show a behavior similar to the one as seen in the experimental observations. However, the current values as calculated are very small as compared to experimental values of the currents. This type of behavior is expected, since the calculated $\mathrm{I}-\mathrm{V}$ characteristics is for a single $\mathrm{Cu}-\mathrm{Se} \mathrm{RTD}$, whereas, the experimental results are due to the collective behavior of a large number of $\mathrm{Cu}$-Se RTDs in parallel.

Further, the PVCR of the Cu-Se RTDs are calculated for different diameters and are shown in tabular form in Table 3.

Calculated values of PVCR of the Cu-Se RTDs of diameters $1 \mu \mathrm{m}, 100 \mathrm{~nm}$ and $40 \mathrm{~nm}$ are 2.01, 2.67 and 3.14, which show an increase in PVCR with decrease in diameters. This behavior is similar to that seen in the I-V curves obtained experimentally.

Hence, it can be inferred that the results obtained from theoretical model of RTD show a behavior similar to that obtained experimentally. However, the theoretical device currents are small in values because, in experimental set-up, several devices are working in parallel while, in theoretical equations, the current for a single device is calculated.

Table 3. Variation of calculated PVCR with diameter.

\begin{tabular}{lc}
\hline Diameter $(\mathrm{nm})$ & PVCR \\
\hline 40 & 3.14 \\
100 & 2.67 \\
1000 & 2.01 \\
\hline
\end{tabular}

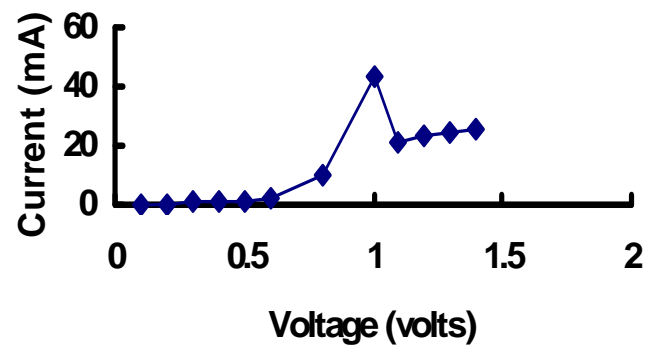

Figure 8.Theoretical I-V characteristics of Cu-Se RTD of 1 $\mu \mathrm{m}$ diameter

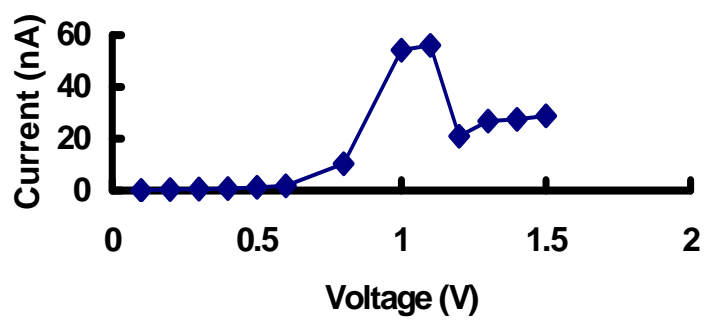

Figure 9. Theoretical I-V characteristics of Cu-Se RTD of $100 \mathrm{~nm}$

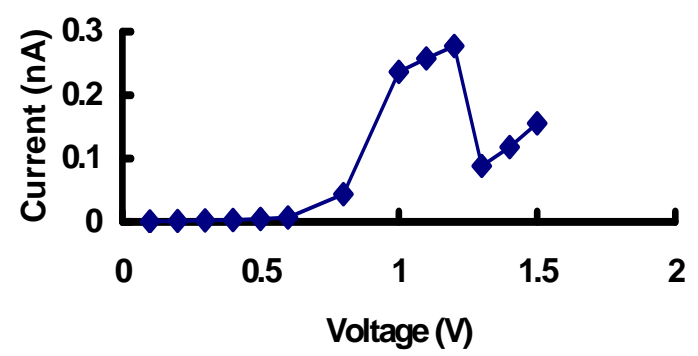

Figure 10. Theoretical I-V characteristics of Cu-Se RTD of $40 \mathrm{~nm}$ diameter

\section{Conclusions}

A suitable model for the template synthesized $\mathrm{Cu}-\mathrm{Se}$ RTDs is proposed. Experimental results have been verified with the help of equations formulated for this model. The results obtained from theoretical model of RTD show a behavior similar to that obtained experimentally. However, the theoretical device currents are small in values and PVCRs show deviation in their values from the experimental values. This is because, in experimental set-up, several devices are working in parallel while, in theoretical equations, the current for a single device is calculated.

\section{REFERENCES}

[1] J. P. Sun, G. I. Haddad, P. Mazumde, and J. N. Schulman, 
Proceedings of the IEEE, Vol. 86, No. 4, pp. 641, 1998.

[2] O. I. Mićić and A. J. Nozik, in Hari Singh Nalwa (Ed.), Colloidal Quantum Dot of III-V Semiconductors, Handbook of Nanostructured Mateials and Nanotechnology,

Academic Press, 2000.

[3] M. Chaudhri, A. Vohra, S. K. Chakarvarti, and R. Kumar, J. mater. Sci., Mater Electron, Vol. 17, pp. 189, 2006.

[4] M. Chaudhri, A. Vohra, and S. K. Chakarvarti, J. Mater. Sci., Mater Electron, Vol. 17, pp. 993, 2006.

[5] M. Chaudhri, A. Vohra, and S. K. Chakarvarti, Physica E, Vol. 40, pp. 849, 2008.

[6] M. Chaudhri, A. Vohra, and S. K. Chakarvarti, Mater. Sci. Engg. B, Vol. 149, No. 7, pp. 641, 2008.

[7] H. D. Vladimir Gavryushin, Functional Combinations in Solid States, 2002. http://www.mtmi.vu.lt/pfk/funkc_dariniai/index.html.

[8] V. V. Moshchalkov, V. Bruyndoncx, L. L. Van, M. J. Van Bael, Y. Bruynseraede, and A. Tonomura, in Hari Singh Nalwa (Ed.), Quantization and Confinement Phenomena in Nanostructured Superconductors, Handbook of Nanostructured Mateials and Nanotechnology, Academic Press, 2000.

[9] Y. J. Choi, I. S. Hwang, J. H. Park, S. Nahm, and J. G. Park, Nanotechnology, Vol. 17, pp. 3775, 2006.

[10] J. Heremans, C. M. Thrush, Y. M. Lin, S. Cronin, Z. Zhang, M. S. Dresselhaus, and J. F. Mansfield, Phys. Rev. B, Vol. 61, pp. 2921, 2000.

[11] M. Li and J. C. Li, , Mater. Lett. Vol. 60, pp. 2526, 2006.

[12] S. Cronin, Z. Zhang, and M. S. Dresselhaus, Phys. Rev. B, Vol. 61, No. 4, pp. 2921, 2000.

[13] S. M. Sze, Physics of Semiconductor Devices. New York,
Wiley, 1981.

[14] V. I. Klimov, Vol. 28, pp. 215, 2003.

[15] S. Ogut, J. R. Chelikowsky, and S. G. Louie, Phys. Rev. Lett., Vol. 79, pp. 1770, 1997.

[16] A. Sigurdardottir, V. Krozer, and H. L. Hartnage, Appl. Phys. Lett., Vol. 67, No. 22, pp. 3313, 1995.

[17] S. H. Kim, , G. Markovich, S. Rezvani, S. H. Choi, S. H., K. L. K. L. Wang, and J. R. Heath, Appl. Phys. Lett., pp. $317,1999$.

[18] B. G. Streetman, "Solid state electronic devices," Prentice-Hall of India Private Limited, New Delhi, 1994.

[19] B. V. Zeghbroeck, "Principles of semiconductor devices," 2004. http://ece-www.colorado.edu/ bart/book.

[20] P. A. Tipler and R. A. Liewellyn, Modern Physics, $3^{\text {rd }}$ Edtion, W. H. Freeman, 1999.

[21] K. Barbalace, 2006. http://Klbprouctions.com/Periodic Table of Elements-Selenium-Se, Environmental Chemistry.com, 1995-2006. Accessed online: 7/13/2006. http:/ Environmental Chemistry.com//yogi/Periodic/Se.html.

[22] C. M. Fang, R. A. De Groot, and G. A. wiegers, Journal of Physics and Chemistry of Solids, Vol. 63, pp. 457, 2002.

[23] N. W. Ashcroft and N. D. Mermin, Solid State Physics, Saunders, 1976.

[24] A. J. Quinn, P. Beecher, D. Iacopino, L. Floyd, G. DeMarzi, E. V. Shechenko, H. Weller, and R G. edmond, Small 1, 613. Vol. 1, pp. 613, 2005.

[25] S. Möller, H. Buhmann, S. F. Godijn, and L. W. Molenkamp, Phys. Rev. Lett., Vol. 81, No. 23, pp. 5197, 1998.

[26] Dielectric Constant References Guide: http://www.asiinstr.com/technal/Dielectric\%20Constants.htm. 